\title{
Heated tobacco product use among US adolescents in 2019: The new tobacco risk
}

\author{
Juhan Lee', Lindsay A. Thompson², Ramzi G. Salloum³
}

\begin{abstract}
INTRODUCTION There is growing public health concern about adolescent use of heated tobacco products (HTPs) after the US Food and Drug Administration approved the leading HTPs, IQOS, as a modified risk tobacco product. Extending the previous studies examining the correlates of HTP use among adolescents, this study aims to investigate potential risk factors for HTP use among US adolescents, including the use of multiple tobacco and flavored tobacco products.

METHODS We analyzed the 2019 National Youth Tobacco Survey $(n=19018)$ and conducted a series of logistic regression models on awareness and use of HTPs as a function of tobacco use status (none, single, dual/poly) and past 30 days flavored tobacco use (e.g. menthol cigarette use, flavored e-cigarettes), controlling for sociodemographics.

RESULTS In multivariable analyses, awareness of HTPs was associated with usual menthol cigarette use $(\mathrm{AOR}=1.77 ; 95 \% \mathrm{CI}: 1.23-2.53)$ and past 30 days flavored tobacco use $(\mathrm{AOR}=1.44 ; 95 \% \mathrm{CI}$ : 1.16-1.80). Risk factors for ever HTP use included single $(\mathrm{AOR}=2.52$; 95\% CI: $1.19-5.33)$ and dual/poly tobacco use (AOR=4.94; 95\% CI: 2.56-9.54), usual menthol cigarette use (AOR=2.50; 95\% CI: 1.66-3.76), and past 30 days flavored tobacco use (AOR=1.61; 95\% CI: $1.07-$ 2.44). Risk factors for current HTP use included single (AOR $=10.84 ; 95 \%$ CI: $6.72-17.49)$ and dual/poly tobacco use (AOR=31.96; 95\% CI: $17.79-57.43)$, and usual menthol cigarette use ( $\mathrm{AOR}=2.50 ; 95 \% \mathrm{CI}: 1.63-3.85)$.

ConcLusıons This study documents HTP use in adolescents and contributes insight and urgency into prioritizing at-risk adolescents for interventions, including current users of other tobacco products and flavored tobacco users.
\end{abstract}

\section{AFFILIATION \\ 1 Department of Health Education and Behavior, College of Health and Human Performance, University of Florida, Gainesville, United States \\ 2 Department of Pediatrics, College of Medicine, University of Florida, \\ Gainesville, United States \\ 3 Department Health Outcomes and Biomedical Informatics, College of Medicine, University of Florida, Gainesville, United States}

\section{CORRESPONDENCE TO}

Juhan Lee. Department of Health Education and Behavior, College of Health and Human Performance, University of Florida, FL 32608, Gainesville, United States. E-mail: juhan.j.lee@ufl.edu ORCID ID: https://orcid.org/0000-0003-08603327

\section{KEYWORDS}

tobacco, youth, heated tobacco product, National Youth Tobacco Survey (NYTS)

Received: 22 September 2020 Revised: 15 November 2020 Accepted: 16 November 2020

\section{INTRODUCTION}

Heated tobacco products (HTPs) are electronic devices that heat tobacco-filled sticks wrapped in paper to generate a nicotine-containing aerosol ${ }^{1,2}$. There are a number of different HTPs that vary by mechanism and heating source, including carbonheated tobacco products (CHTPs) that use carbon sources for heating ${ }^{3}$, and electronic HTPs that use an electrical heating source ${ }^{4,5}$. Since 2014, several tobacco companies including Philip Morris International,
British American Tobacco, RJ Reynolds Tobacco, and Japan Tobacco International, have been aggressively marketing their HTPs in the global market, and promoting them as 'less harmful' products'

In January 2020, the sale of IQOS (HTP brand marketed by PMI) and Eclipse (marketed by RJ Reynolds) was authorized in the United States? The US Food and Drug Administration (FDA) first authorized HTPs in April 2019, and in July 2020 designated the leading HTP brand, IQOS, as 
a modified risk tobacco product (i.e. authorized under an exposure modification order), enabling its marketing as a reduced exposure product, aligned with the company's claims of harm reduction ${ }^{8}$. However, the concept of 'reduced exposure' (e.g. only suggesting a product contains reduced levels of certain chemicals) may be easily misconstrued by consumers, particularly by youth and young adults, as 'reduced harm'. This perception of 'reduced harm' suggests that such products significantly reduce the risk of tobacco-related diseases ${ }^{9,10}$. This issue may be of particular concern with new tobacco products since it could affect the susceptibility of youth and young adults to these products ${ }^{10}$.

Although the health consequences of HTP use remain uncertain ${ }^{11}$, there is growing public health concern about potential adolescent initiation and use of $\mathrm{HTPs}^{12}$. Previous studies identified several correlates of HTP use among US adolescents including current tobacco use (e.g. cigarettes, e-cigarettes), being Hispanic, and familial use of HTPs ${ }^{13,14}$; however, there is still a knowledge gap regarding other potential risk factors of HTP use among US adolescents. For example, the briefing document from PMI indicated that IQOS may attract those who favor menthol cigarettes ${ }^{15}$. Also, multiple tobacco product use has been associated with HTP use among Korean adolescents $^{16,17}$. Nonetheless, these associations are yet to be examined among adolescents in the US. Therefore, this study aimed to examine the association between the use of multiple tobacco products and flavored tobacco products with HTP use among a US nationally representative sample of adolescents.

\section{METHODS}

\section{Dataset and study participants}

We analyzed data from the 2019 National Youth Tobacco Survey (NYTS), an annual cross-sectional survey representing the US population of middle and high school students. The NYTS uses multi-stage stratified sampling with respondents representing all middle and high school students in the US. The overall weighted response rate was $66.3 \%{ }^{18}$. Our analytic sample included all respondents in the 2019 NYTS $(n=19018)$.

\section{Measures}

Outcomes of interest

HTP awareness and use were assessed by the following statements:

'The next section is about "heated tobacco products". Some people refer to these products as "heat-not-burn" tobacco products. "Heated tobacco products" heat tobacco sticks or capsules to produce a vapor. They are different from e-cigarettes, which heat a liquid to produce a vapor. Some brands of "heated tobacco products" include iQOS, glo, and Eclipse'.

Respondents were then asked if they have heard of heated tobacco products (awareness, with response options: 'no', 'yes', and 'don't know/not sure'), ever tried a heated tobacco product, even just one time (ever use, with response options: 'no', 'yes', and 'don't know/not sure') and on how many days they used HTPs during the past 30 days (current use: use $\geq 1$ day in the past 30 days). We used these measures as outcomes of interests.

\section{Predictors of interest}

Respondents were also asked on how many days they used other tobacco products in the past 30 days, including cigarettes, e-cigarettes, and cigars. We categorized those who used the product for more than 1 day in the past 30 days as a current user of tobacco products and counted the number of tobacco products they currently used. We then categorized respondents as using none, single ( 1 product), and dual/poly users ( $\geq 2$ products).

Respondents were also asked about the past 30 days menthol cigarette use, using the question: 'During the past 30 days, were the cigarettes that you usually smoked menthols?'; menthol cigarette users were identified as those who responded affirmatively to this question. The past 30 days flavored tobacco product use (e.g. cigars, e-cigarettes, hookah) was assessed using the question: 'Which of the following tobacco products that you used in the past 30 days were flavored to taste like menthol (mint), alcohol (wine, cognac), candy, fruit, chocolate or any other flavors?'. We categorized those who selected any of the tobacco products (except for HTPs) as 'past 30 days' flavored tobacco users.

\section{Covariates}

For potential confounders, we used grade level (middle or high school), sex (female or male), race/ ethnicity (non-Hispanic White, non-Hispanic Black, 
Hispanic, or non-Hispanic other), and familial use of tobacco products (no or yes) $)^{13}$.

\section{Statistical analysis}

We performed descriptive analyses to obtain the sample characteristics and calculated weighted proportions and 95\% confidence intervals (CI) for awareness and use of HTPs by tobacco use status (none, single, dual/poly), past 30 days flavored tobacco use (e.g. menthol cigarettes, flavored e-cigarettes), as well as sociodemographics. We further fitted logistic regression models of the awareness and use of HTPs as a function of current tobacco product use status and the use of other flavored tobacco products, controlling for sociodemographic factors, and family members' HTP use. We took into account the complex sampling design of the NYTS ${ }^{18}$ using Stata 16.0 (College Station, TX), with two-sided $\mathrm{p}<0.05$ considered significant. This secondary-analysis study obtained ethical approval as 'exempt' at the University of Florida.

\section{RESULTS}

Table 1 shows the sample characteristics and prevalence of HTP awareness and use, by associated factors. Among all respondents $(\mathrm{n}=19018), 12.8 \%$ reported awareness of HTPs (unweighted $n=2390$ ), $2.3 \%(n=398)$ reported ever use, and 1.6\% $(n=291)$ reported current use of HTPs. In terms of the current tobacco use status (not including HTPs), of all respondents, $14.8 \%(n=2685)$ reported single tobacco product use and $7.7 \%(n=1357)$ reported currently using two or more tobacco products. Furthermore, $16.0 \%(n=2954)$ reported past 30 days use of any flavored tobacco products (e.g. cigars, e-cigarettes) and $1.7 \%(n=292)$ reported past 30 days use of menthol cigarettes.

Dual/poly tobacco product users, compared to non-users and single tobacco product users, reported the highest rates of awareness of HTPs $(18.0 \%$, weighted; vs $12.3 \%$ of non-users and $11.5 \%$ of single tobacco product users), ever use ( $11.0 \%$ vs $1.0 \%$ of non-users and $3.6 \%$ of single product users), and current use $(10.5 \%$ vs $0.3 \%$ of non-users and $2.7 \%$ of single product users). Usual menthol cigarette users (vs none users) reported higher awareness (29.1\% vs $12.5 \%)$, ever use $(23.1 \%$ vs $2.0 \%)$, and current use of HTPs (19.7\% vs 1.3\%). Past 30 days flavored tobacco users (vs none users) also reported higher level of awareness (15.7\% vs $12.2 \%)$, ever use $(7.9 \%$ vs $1.3 \%)$ and current use of HTPs (6.7\% vs $0.6 \%)$.

Table 2 shows the likelihood of awareness and use of HTPs by several associated factors. Higher odds of awareness of HTPs were associated with familial use of HTPs (AOR=4.78; 95\% CI: 3.207.13), usual menthol cigarette use $(\mathrm{AOR}=1.77$;

Table 1. Sample characteristics and prevalence of heated tobacco products (HTPS) use among US adolescents $(\mathbf{N}=19018)$

\begin{tabular}{|c|c|c|c|c|c|c|c|}
\hline \multirow[t]{3}{*}{ Characteristics } & Total & \multicolumn{2}{|c|}{ Awareness of HTPS } & \multicolumn{2}{|c|}{ Ever use of HTPS } & \multicolumn{2}{|c|}{ Current use of HTPS } \\
\hline & $n=19018$ & \multicolumn{2}{|c|}{$n=2390 ; 12.8 \%$ (weighted) } & \multicolumn{2}{|c|}{$n=398 ; 2.3 \%$} & \multicolumn{2}{|c|}{$n=291 ; 1.6 \%$} \\
\hline & $n$ (weighted \%) & $\begin{array}{l}\text { Weighted \% } \\
(95 \% \text { CI })^{a}\end{array}$ & $p$ & $\begin{array}{l}\text { Weighted \% } \\
(95 \% \text { CI })^{a}\end{array}$ & $p^{b}$ & $\begin{array}{l}\text { Weighted \% } \\
(95 \% \text { CI })^{a}\end{array}$ & $p^{b}$ \\
\hline Current tobacco use $\mathrm{e}^{\mathrm{c}}$ & & & $<0.001$ & & $<0.001$ & & $<0.001$ \\
\hline None (0) & $14611(77.5)$ & $12.3(11.2-13.6)$ & & $1.0(0.5-2.1)$ & & $0.3(0.2-0.4)$ & \\
\hline Single (1 product) & 2685 (14.8) & $11.5(10.0-13.2)$ & & $3.6(2.7-4.6)$ & & $2.7(2.0-3.6)$ & \\
\hline Dual/poly ( $\geq 2$ products) & $1357(7.7)$ & $18.0(15.3-21.0)$ & & $11.0(8.3-14.5)$ & & $10.5(8.0-13.7)$ & \\
\hline Grade level & & & 0.028 & & 0.006 & & 0.151 \\
\hline Middle school & $8837(44.1)$ & $14.2(13.2-15.3)$ & & $1.6(1.3-2.1)$ & & $1.4(1.1-1.8)$ & \\
\hline High school & 10097 (55.9) & 11.7 (9.9-13.8) & & $2.9(1.8-4.6)$ & & $1.7(1.3-2.2)$ & \\
\hline Sex & & & 0.075 & & 0.014 & & 0.269 \\
\hline Female & $9099(48.0)$ & $11.9(11.1-12.8)$ & & $1.6(1.3-2.0)$ & & $1.4(1.1-1.9)$ & \\
\hline Male & $9.803(52.0)$ & $13.6(11.8-15.7)$ & & $3.0(1.8-5.0)$ & & $1.7(1.3-2.2)$ & \\
\hline
\end{tabular}


Table 1. Continued

\begin{tabular}{|c|c|c|c|c|c|c|c|}
\hline \multirow[t]{3}{*}{ Characteristics } & Total & \multicolumn{2}{|c|}{ Awareness of HTPS } & \multicolumn{2}{|c|}{ Ever use of HTPS } & \multicolumn{2}{|l|}{ Current use of } \\
\hline & $n=19018$ & \multicolumn{2}{|c|}{$n=2390 ; 12.8 \%$ (weighted) } & \multicolumn{2}{|c|}{$n=398 ; 2.3 \%$} & \multicolumn{2}{|c|}{$n=291 ; 1.6 \%$} \\
\hline & $n$ (weighted \%) & $\begin{array}{l}\text { Weighted \% } \\
(95 \% \text { CI })^{a}\end{array}$ & $p$ & $\begin{array}{l}\text { Weighted \% } \\
(95 \% \text { CI })^{a}\end{array}$ & $p^{b}$ & $\begin{array}{l}\text { Weighted \% } \\
(95 \% \text { CI })^{\mathrm{a}}\end{array}$ & $p^{b}$ \\
\hline Race/Ethnicity & & & 0.859 & & 0.127 & & 0.044 \\
\hline Non-Hispanic White & $9351(56.2)$ & $12.8(11.6-14.1)$ & & $2.3(1.6-3.4)$ & & $1.3(1.0-1.8)$ & \\
\hline Non-Hispanic Black & $2430(13.3)$ & $12.2(10.9-13.6)$ & & $2.0(1.3-3.0)$ & & $1.8(1.3-2.5)$ & \\
\hline Hispanic & $5564(25.0)$ & $13.0(10.9-15.3)$ & & $2.8(1.7-4.8)$ & & $2.1(1.6-2.8)$ & \\
\hline Non-Hispanic Other & $1227(5.5)$ & $12.4(10.2-15.0)$ & & $1.4(0.8-2.6)$ & & $1.2(0.5-2.5)$ & \\
\hline $\begin{array}{l}\text { Familial heated } \\
\text { tobacco product use }\end{array}$ & & & $<0.001$ & & $<0.001$ & & $<0.001$ \\
\hline No & 18814 (98.9) & $12.5(11.4-13.6)$ & & $2.1(1.4-3.0)$ & & $1.4(1.1-1.7)$ & \\
\hline Yes & $204(1.1)$ & $43.1(32.7-54.2)$ & & $28.2(18.6-40.3)$ & & $22.3(15.1-31.6)$ & \\
\hline $\begin{array}{l}\text { Past } 30 \text { days menthol } \\
\text { cigarette use }^{\mathrm{e}}\end{array}$ & & & $<0.001$ & & $<0.001$ & & $<0.001$ \\
\hline $\mathrm{No}^{f}$ & $18726(98.3)$ & $12.5(11.5-13.6)$ & & $2.0(1.4-2.9)$ & & $1.3(1.1-1.5)$ & \\
\hline Yes & $292(1.7)$ & $29.1(20.6-39.3)$ & & $23.1(15.8-32.5)$ & & $19.7(13.3-28.2)$ & \\
\hline $\begin{array}{l}\text { Past } 30 \text { days flavored } \\
\text { tobacco product use }{ }^{g}\end{array}$ & & & $<0.001$ & & $<0.001$ & & $<0.001$ \\
\hline No & $16064(84.0)$ & $12.2(11.2-13.4)$ & & $1.3(0.7-2.3)$ & & $0.6(0.5-0.8)$ & \\
\hline Yes $^{h}$ & $2954(16.0)$ & $15.7(13.5-18.3)$ & & $7.9(6.2-10.1)$ & & $6.7(5.1-8.8)$ & \\
\hline
\end{tabular}

a Weighted estimates and 95\% Cl took into account the complex survey design using Taylor series variance estimation. b Rao-Scott adjusted chi-squared test was used to detect significant association between groups. c Includes current use of cigarettes, e-cigarettes, cigars, smokeless tobacco (e.g. chewing tobacco, snuff, or dip), hookah, roll-your-own cigarettes, pipe, snus, dissolvable tobacco products, and bidis. d Assessed with the question: 'Does anyone who lives with you now [...] use heated tobacco products?'. e Assessed with the question: 'Menthol cigarettes are cigarettes that taste like mint. During the past 30 days, were the cigarettes that you usually smoked menthol?'. $f$ Includes 'no', 'not sure' and 'not past 30 days cigarette smokers'. g Assessed with the question: 'Which of the following tobacco products that you used in the past 30 days were flavored to taste like menthol (mint), alcohol (wine, cognac), candy, fruit, chocolate, or any other flavors? (select one or more)'. h Includes 'cigars, cigarillos, or little cigars', 'chewing tobacco, snuff, or dip', 'e-cigarettes', 'tobacco in a hookah or waterpipe', 'pipe filled with tobacco (not waterpipe)', 'snus', 'dissolvable tobacco products', 'bidis', 'roll-your-own cigarettes'; not including heated tobacco products.

Table 2. Results of logistic regression models of heated tobacco products (HTPS) use among US adolescents $(\mathbf{N}=19018)$

\begin{tabular}{|c|c|c|c|c|c|c|}
\hline \multirow[t]{2}{*}{ Characteristics } & \multicolumn{2}{|c|}{ Awareness of HTPS $(n=2390)$} & \multicolumn{2}{|c|}{ Ever use of HTPS $(n=398)$} & \multicolumn{2}{|c|}{ Current use of HTPS $(n=291)$} \\
\hline & AOR $(95 \% \mathrm{CI})$ & $p$ & $\operatorname{AOR}(95 \% \mathrm{CI})$ & $p$ & AOR $(95 \%$ CI $)$ & $p$ \\
\hline \multicolumn{7}{|l|}{ Current tobacco use ${ }^{a}$} \\
\hline None (0) & Ref. & & Ref. & & Ref. & \\
\hline Single (1 product) & $0.76(0.59-0.98)$ & 0.033 & $2.52(1.19-5.33)$ & 0.017 & 10.84 (6.72-17.49) & $<0.001$ \\
\hline Dual/poly ( $\geq 2$ products) & $0.96(0.71-1.28)$ & 0.769 & $4.94(2.56-9.54)$ & $<0.001$ & $31.96(17.79-57.43)$ & $<0.001$ \\
\hline \multicolumn{7}{|l|}{ Grade level } \\
\hline Middle school & Ref. & & Ref. & & Ref. & \\
\hline High school & $0.77(0.63-0.95)$ & 0.015 & $1.11(0.59-2.11)$ & 0.737 & $0.54(0.39-0.74)$ & $<0.001$ \\
\hline \multicolumn{7}{|l|}{ Sex } \\
\hline Female & Ref. & & Ref. & & Ref. & \\
\hline Male & $1.13(0.96-1.34)$ & 0.151 & $1.81(1.06-3.10)$ & 0.031 & $0.94(0.64-1.39)$ & 0.759 \\
\hline
\end{tabular}


Table 2. Continued

\begin{tabular}{|c|c|c|c|c|c|c|}
\hline \multirow[t]{2}{*}{ Characteristics } & \multicolumn{2}{|c|}{ Awareness of HTPS $(n=2390)$} & \multicolumn{2}{|c|}{ Ever use of HTPS ( $n=398)$} & \multicolumn{2}{|c|}{ Current use of HTPS $(n=291)$} \\
\hline & $\operatorname{AOR}(95 \% \mathrm{CI})$ & $p$ & AOR $(95 \%$ CI $)$ & $p$ & $\operatorname{AOR}(95 \% \mathrm{CI})$ & $p$ \\
\hline \multicolumn{7}{|l|}{ Race/Ethnicity } \\
\hline Non-Hispanic White & Ref. & & Ref. & & Ref. & \\
\hline Non-Hispanic Black & $0.95(0.82-1.11)$ & 0.518 & $0.91(0.54-1.54)$ & 0.728 & $1.42(0.90-2.23)$ & 0.127 \\
\hline Hispanic & $1.00(0.85-1.17)$ & 0.993 & $1.31(0.91-1.87)$ & 0.140 & $1.62(1.10-2.37)$ & 0.015 \\
\hline Non-Hispanic Other & $1.00(0.80-1.27)$ & 0.968 & $0.82(0.36-1.86)$ & 0.636 & $1.51(0.60-3.79)$ & 0.380 \\
\hline \multicolumn{7}{|c|}{$\begin{array}{l}\text { Familial heated tobacco } \\
\text { product use }^{b}\end{array}$} \\
\hline No & Ref. & & Ref. & & Ref. & \\
\hline Yes & $4.78(3.20-7.13)$ & $<0.001$ & $9.78(5.65-16.94)$ & $<0.001$ & $6.07(3.66-10.07)$ & $<0.001$ \\
\hline \multicolumn{7}{|l|}{$\begin{array}{l}\text { Past } 30 \text { days menthol } \\
\text { cigarette use }^{c}\end{array}$} \\
\hline $\mathrm{No}^{d}$ & Ref. & & Ref. & & Ref. & \\
\hline Yes & $1.77(1.23-2.53)$ & 0.002 & $2.50(1.66-3.76)$ & $<0.001$ & $2.50(1.63-3.85)$ & $<0.001$ \\
\hline \multicolumn{7}{|c|}{$\begin{array}{l}\text { Past } 30 \text { days flavored, non- } \\
\text { cigarette tobacco product use }\end{array}$} \\
\hline No & Ref. & & Ref. & & Ref. & \\
\hline Yes $^{f}$ & $1.44(1.16-1.80)$ & 0.002 & $1.61(1.07-2.44)$ & 0.024 & $1.34(0.88-2.03)$ & 0.169 \\
\hline
\end{tabular}

'dissolvable tobacco products', 'bidis', 'roll-your-own cigarettes'; not including heated tobacco products.

95\% CI: $1.23-2.53)$, and past 30 days flavored tobacco use $(\mathrm{AOR}=1.44 ; 95 \% \mathrm{CI}: 1.16-1.80)$. Risk factors for ever HTP use included single tobacco use $(\mathrm{AOR}=2.52 ; 95 \% \mathrm{CI}: 1.19-5.33)$ and dual/poly tobacco use $(\mathrm{AOR}=4.94 ; 95 \% \mathrm{CI}: 2.56-9.54)$, being male $(\mathrm{AOR}=1.81 ; 95 \% \mathrm{CI}: 1.06-3.10)$, familial use of HTPs (AOR=9.78; 95\% CI: 5.65-16.94), usual menthol cigarette use $(\mathrm{AOR}=2.50 ; 95 \% \mathrm{CI}$ : 1.66-3.76), and past 30 days flavored tobacco use (AOR $=1.61 ; 95 \%$ CI: 1.07-2.44). Risk factors for current HTP use included single $(\mathrm{AOR}=10.84 ; 95 \%$ CI: $6.72-17.49$ ) and dual/poly tobacco use (vs none) (AOR=31.96; 95\% CI: 17.79-57.43), being Hispanic $(\mathrm{AOR}=1.62 ; 95 \% \mathrm{CI}: 1.10-2.37)$, familial use of HTPs $(A O R=6.07 ; 95 \%$ CI: 3.66-10.07), and usual menthol cigarette use $(\mathrm{AOR}=2.50 ; 95 \%$ CI: $1.63-$ $3.85)$.

\section{DISCUSSION}

We believe this is the first national study in the US to examine the association between knowledge and use of HTPs and other tobacco use status (mono/ dual/poly tobacco use), as well as other flavored tobacco use (menthol cigarettes and flavored e-cigarettes), consistent with previous findings ${ }^{12,13,15}$. This study documents HTP use in adolescents and adds insight and urgency into prioritizing targeted interventions for adolescents who are current users of other tobacco products, flavored tobacco product users, Hispanic adolescents, and those whose family members use HTPs. Of particular concern for children is the association between HTP use and poly-tobacco use, which echoes previous findings among Korean adolescents $^{16,17}$. The underlying mechanisms of polytobacco use among adolescents may be explained by several frameworks such as the neurobiological framework ${ }^{19}$ and the social/contextual/situational frameworks ${ }^{20,21}$. Accordingly, it is important to understand the unique context of HTP use (i.e. why, when, where, with whom it is used, and perceptions/ 
attitudes toward HTPs) and to incorporate contextual factors in the development of prevention strategies for youth tobacco use such as educational campaigns ${ }^{13}$.

Another potential concern related to HTP use is flavors. The underlying mechanism related to the co-use of flavored tobacco products and HTPs is still unclear, yet it is expected that flavors in HTP may attract flavored tobacco users. For example, the International Tobacco Control Policy Evaluation Project-Japan survey found adult HTP users who were currently smoking cigarettes preferred menthol-flavored $\mathrm{HTPs}^{22}$. We also found that among current HTP users, $21.2 \%$ reported that they used flavored HTPs in the past 30 days (results not shown). In the current US market, only mentholflavored HTPs are available ${ }^{1}$, but tobacco companies may be considering options for introducing other flavors in the future as they have done with other tobacco products ${ }^{1}$. Even though the proportion of flavor use remains lower for HTPs compared with other tobacco products (e.g. e-cigarettes), it is important to continuously monitor the flavored product use in $\mathrm{HTPs}^{23}$ and potential future marketing strategies (e.g. introducing new flavors) as flavors are the primary reason why youth are attracted to tobacco products ${ }^{15}$.

Of note, we found specific risk factors associated with the experimentation and current use of HTPs. For example, being male was associated with experimentation, but not current use of e-cigarettes. In general, boys are more likely than girls to use tobacco products ${ }^{24}$, and a PMI briefing document revealed that adult males were more likely to be attracted to HTPs than females ${ }^{15}$. Also, those who currently used any flavored tobacco products (except for menthol cigarettes) were more likely to experiment with HTPs but did not continue to use them. Adolescents who are using flavored tobacco products may have a higher tendency to experiment with new tobacco products in general ${ }^{25}$. Further, even though the likelihood of experimentation was not significantly different for Hispanics compared with non-Hispanic White youth, Hispanics were more likely to currently use HTPs. A previous report suggested that Hispanic adults were more attracted to $\mathrm{HTPs}^{15}$, possibly due to social norms or acculturation ${ }^{26}$. However, due to the paucity of studies on HTPs, the underlying mechanisms explaining these factors, particularly as they relate to experimentation and escalation of HTP use, are still unclear. More research is needed to examine the neurobiological and psychosocial underlying mechanisms that explain these behavioral patterns.

\section{Limitations}

There are some limitations in this study. First, we cannot rule out the potential for self-report bias. Since HTPs were newly introduced to the US market, survey participants may have confused e-cigarettes with $\mathrm{HTPs}^{13}$. Thus, it may be important for future surveys to include pictures of HTPs to minimize confusion with other emerging tobacco products. Second, as this study used an observational cross-sectional design, we cannot infer any causality or temporality from our findings. Third, we acknowledge the likelihood for unobserved potential confounding in the survey such as perceptions and attitudes toward HTPs ${ }^{12}$ or early adopter propensity ${ }^{12}$.

\section{CONCLUSIONS}

Healthcare professionals and educators should screen and warn adolescents and their families about all forms of tobacco use, including $\mathrm{HTPs}^{27}$. Tobacco regulatory policies on HTPs are likewise critical ${ }^{6,8}$. Even if the rates are arguably low as of 2019 , as the availability of HTPs and marketing practices (e.g. advertisements) increases, the awareness and use among adolescents is expected to increase in the future. For example, a study from Japan reported HTP use increased from $0.2 \%$ in 2015 to $11.3 \%$ in 2019 , likely due to the increased availability of HTPs over this time period ${ }^{28}$. Thus, it is important to monitor changes in HTP availability as well as individuals' awareness and use of HTPs over time. As with other emerging nicotine products like e-cigarettes, adolescents may be drawn to HTPs due to industry marketing strategies that add attractive flavors and support sleek designs ${ }^{1,23}$. Therefore, it is important to proactively develop and enforce regulatory policies that include product packaging and advertising restrictions, minimum age requirements, and tobacco retailer licensing and zoning. ${ }^{8}$. The recent FDA authorization of IQOS (one of the HTP brands) as Modified Risk Tobacco Products (MRTPs) mandates the urgent need for continuous surveillance and prevention in partnership with families, schools, clinicians, and policymakers. 


\section{REFERENCES}

1. McKelvey K, Popova L, Kim M, et al. Heated tobacco products likely appeal to adolescents and young adults. Tob Control. 2018;27(Suppl 1):s41-s47. doi:10.1136/tobaccocontrol-2018-054596

2. Churchill V, Weaver SR, Spears CA, et al. IQOS debut in the USA: Philip Morris International's heated tobacco device introduced in Atlanta, Georgia. Tob Control. 2020. doi:10.1136/tobaccocontrol-2019-055488

3. Iskandar AR, Martin F, Leroy P, et al. Comparative biological impacts of an aerosol from carbon-heated tobacco and smoke from cigarettes on human respiratory epithelial cultures: A systems toxicology assessment. Food Chem Toxicol. 2018;115:109-126. doi:10.1016/j.fct.2018.02.063

4. Simonavicius E, McNeill A, Shahab L, Brose LS. Heat-not-burn tobacco products: A systematic literature review. Tob Control. 2019;28(5):582-594. doi:10.1136/tobaccocontrol-2018-054419

5. Mallock N, Pieper E, Hutzler C, Henkler-Stephani F, Luch A. Heated Tobacco Products: A Review of Current Knowledge and Initial Assessments. Front Public Heal. 2019;7:287. doi:10.3389/fpubh.2019.00287

6. Bialous SA, Glantz SA. Heated tobacco products: Another tobacco industry global strategy to slow progress in tobacco control. Tob Control. 2018;27(Suppl 1):s111-s117. doi:10.1136/tobaccocontrol-2018-054340

7. Centers for Disease Control and Prevention. Heated Tobacco Products. https://www.cdc.gov/tobacco/ basic_information/heated-tobacco-products/index.html. Updated July 17, 2020. Accessed November 15, 2020.

8. U.S. Food and Drug Administration. FDA Authorizes Marketing of IQOS Tobacco Heating System with 'Reduced Exposure' Information. https://www.fda.gov/ news-events/press-announcements/fda-authorizesmarketing-iqos-tobacco-heating-system-reducedexposure-information. Published July 7, 2020. Accessed November 15, 2020.

9. Popova L, Lempert LK, Glantz SA. Light and mild redux: Heated tobacco products' reduced exposure claims are likely to be misunderstood as reduced risk claims. Tob Control. 2018;27(Suppl 1):s87-s95. doi:10.1136/tobaccocontrol-2018-054324

10. El-Toukhy S, Baig SA, Jeong M, Byron MJ, Ribisl KM, Brewer NT. Impact of modified risk tobacco product claims on beliefs of US adults and adolescents. Tob Control. 2018;27:s62-s69. doi:10.1136/tobaccocontrol-2018-054315

11. Auer R, Concha-Lozano N, Jacot-Sadowski I, Cornuz J, Berthet A. Heat-Not-Burn Tobacco Cigarettes: Smoke by Any Other Name. JAMA Intern Med. 2017;177(7):10501052. doi:10.1001/jamainternmed.2017.1419

12. Nyman AL, Weaver SR, Popova L, et al. Awareness and use of heated tobacco products among US adults, 2016-2017. Tob Control. 2018;27(Suppl 1):s55-s61. doi:10.1136/tobaccocontrol-2018-054323
13. Dai H. Heated tobacco product use and associated factors among U.S. youth, 2019. Drug Alcohol Depend. 2020;214:108150. doi:10.1016/j.drugalcdep.2020.108150

14. Czoli CD, White CM, Reid JL, Oconnor RJ, Hammond D. Awareness and interest in IQOS heated tobacco products among youth in Canada, England and the USA. Tob Control. 2020;29(1):89-95. doi:10.1136/tobaccocontrol-2018-054654

15. Philip Morris Products S.A. Tobacco Heating System (IQOS) Briefing Document. https://www.fda.gov/ media/110377/download. Published December 2017. Accessed August 19, 2020.

16. Lee A, Lee KS, Park H. Association of the use of a heated tobacco product with perceived stress, physical activity, and internet use in Korean adolescents: A 2018 national survey. Int J Environ Res Public Health. 2019;16(6):965. doi:10.3390/ijerph16060965

17. Kang H, Cho S Il. Heated tobacco product use among Korean adolescents. Tob Control. 2019;0:1-3. doi:10.1136/tobaccocontrol-2019-054949

18. Centers for Disease Control and Prevention. 2019 National Youth Tobacco Survey: Methodology Report. Atlanta, GA: U.S. Department of Health and Human Services, Centers for Disease Control and Prevention, National Center for Chronic Disease Prevention and Health Promotion, Office on Smoking and Health; 2019. https://www.cdc.gov/tobacco/data_statistics/surveys/ nyts/index.htm. Accessed November 15, 2020.

19. Vanyukov MM, Ridenour TA. Common liability to drug addictions: Theory, research, practice. Drug Alcohol Depend. 2012;123:S1-S1. doi:10.1016/j.drugalcdep.2012.01.005

20. Pacek LR, Wiley JL, Joseph McClernon F. A conceptual framework for understanding multipletobacco product use and the impact of regulatory action. Nicotine Tob Res. 2019;21(3):268-277. doi:10.1093/ntr/nty129

21. McQuoid J, Keamy-Minor E, Ling PM. A practice theory approach to understanding poly-tobacco use in the United States. Crit Public Health. 2020;30(2):204-219. doi:10.1080/09581596.2018.1541226

22. Sutanto E, Miller C, Smith DM, et al. Prevalence, use behaviors, and preferences among users of heated tobacco products: Findings from the 2018 itc Japan survey. Int J Environ Res Public Health. 2019;16(23):4630. doi:10.3390/ijerph16234630

23. Jenssen BP, Walley SC, McGrath-Morrow SA. Heatnot-burn tobacco products: Tobacco industry claims no substitute for science. Pediatrics. 2018;141(1):e20172383. doi:10.1542/peds.2017-2383

24. Kong G, Kuguru KE, Krishnan-Sarin S. Gender Differences in U.S. Adolescent E-Cigarette Use. Curr Addict Reports. 2017;4(4):422-430. doi:10.1007/s40429-017-0176-5

25. Wang TW, Gentzke AS, Creamer MLR, et al. Tobacco product use and associated factors among middle and high school students-United States, 2019. MMWR Surveill Summ. 2019;68(1):1-22. doi:10.15585/mmwr.ss6812a1 
26. Baezconde-Garbanati L. Monograph 14: Understanding Tobacco-Use Research among Hispanic/Latino Adolescents: A Sociocultural Perspective. https:// cancercontrol.cancer.gov/sites/default/files/2020-06/ m14_15.pdf. Published 2020. Accessed November 15, 2020.

27. Sargent JD, Unger JB, Leventhal AM. Recommendations from the USPSTF for Prevention and Cessation of Tobacco Use in Children and Adolescents. JAMA. 2020;323(16):1563. doi:10.1001/jama.2019.22312

28. Hori A, Tabuchi T, Kunugita N. Rapid increase in heated tobacco product (HTP) use from 2015 to 2019: from the Japan ‘Society and New Tobacco' Internet Survey (JASTIS). Tob Control. 2020. doi:10.1136/tobaccocontrol-2020-055652
CONFLICTS OF INTEREST

The authors have completed and submitted the ICMJE Form for Disclosure of Potential Conflicts of Interest and none was reported.

FUNDING

There was no source of funding for this research.

PROVENANCE AND PEER REVIEW

Not commissioned; externally peer reviewed. 